\title{
Haemogram Parameters in the Development of Retinopathy of Prematurity
}

\author{
Muberra Akdogan'1, Didem Arda Demirag'2, Ipek Guney Varal'3, Sadık Gorkem Cevik², \\ Yasemin Ustundag4
}

${ }^{1}$ Department of Ophthalmology, University of Health Sciences (SBU) Bursa Yüksek İhtisas Training and Research Hospital, Bursa, Turkey

${ }^{2}$ The Ministry of Health, Bursa Zubeyde Hanım Maternity Hospital, Bursa, Turkey

${ }^{3}$ Newborn Clinic, University of Health Sciences, Bursa Yuksek Ihtisas Training and Research Hospital, Bursa, Turkey

${ }^{4}$ Deparment of Clinical Biochemistry, University of Health Sciences, Bursa Yuksek Ihtisas Training and Research Hospital, Bursa, Turkey

Email:mbrakdogan@yahoo.com

How to cite this paper: Akdogan, M., Demirag, D.A., Varal, I.G., Cevik, S.G. and Ustundag, Y. (2018) Haemogram Parameters in the Development of Retinopathy of Prematurity. Open Journal of Ophthalmology, 8, 75-83.

https://doi.org/10.4236/ojoph.2018.82011

Received: March 23, 2018

Accepted: May 5, 2018

Published: May 8, 2018

Copyright $\odot 2018$ by authors and Scientific Research Publishing Inc. This work is licensed under the Creative Commons Attribution International License (CC BY 4.0).

http://creativecommons.org/licenses/by/4.0/

\begin{abstract}
Purpose: Retinopathy of prematurity (ROP), an abnormal proliferation of retinal vessels in premature infants with low birth weight, develops due to many factors. This study investigated a possible correlation between haematological parameters and ROP development. Method: This study included 189 infants without ROP and 128 with ROP. All were born at 35 weeks' gestation or earlier, had a CBC drawn within 72 hours of birth, and had haemogram data for the first month. Haemoglobin $(\mathrm{Hb})$, haematocrit $(\mathrm{Hct})$, mean corpuscular volume $(\mathrm{MCV})$, mean corpuscular haemoglobin $(\mathrm{MCH})$, mean corpuscular haemoglobin concentration (MCHC), red cell distribution width (RDW), platelet counts (PLT), mean platelet volume (MPV) and platelet distribution width (PDW) values were obtained from hospital data and retrospectively analysed. Results: The mean gestational age was 31 weeks and 29 weeks for the control and ROP groups, respectively; the mean birth weights were $1757 \mathrm{~g}$ and $1332 \mathrm{~g}$, respectively. The ROP group's birth $\mathrm{Hb}, \mathrm{MCV}$ and RDW were significantly lower than the control group $(p<0.001)$, whereas PLT and MPV were significantly higher $(p<0.001)$. The ROP group's Hb and PLT in the first month were significantly lower than the control group $(p<0.001)$, whereas RDW, MPV and PDW were significantly higher $(p<0.001)$. Conclusion: Premature infants with ROP had lower $\mathrm{Hb}$ and increased platelet, MPV and PDW in early postnatal life than infants without ROP. In the first month, when ROP develops, low PLT, PDW and Hb and high MPV could be indicators for ROP diagnosis, follow-up and treatment.
\end{abstract}

\section{Keywords}

Retinopathy of Prematurity (ROP), Platelet, Erythrocyte 


\section{Introduction}

Retinopathy of prematurity (ROP) is a disease caused by abnormal proliferation of retinal vessels in infants with low birth weight and preterm birth [1] [2]. Despite the significant improvement in the conditions of neonatal intensive care and the advancements in screening and treatment, ROP still emerges as a cause of the main ophthalmologic problem in the later lives of premature infants. Advanced stage ROP may be associated with vision loss ranging from severe vision loss to full blindness. In the USA alone, 14,000 - 16,000 infants have different stages of ROP, and more than 50,000 children worldwide are blind due to ROP [3] [4]. ROP is the most important global cause of visual impairment and blindness in premature infants [5].

Retinopathy of prematurity is a two-phase disease consisting of phase 1 (in utero 22 - 30 weeks, hyperoxic phase-angiogenesis phase) and phase 2 (in utero 31 - 45 weeks, hypoxic phase-vasculogenesis phase). Phase 1 infants, who are normally in a hypoxic environment in the mother's womb, are exposed to high concentrations of oxygen in the atmosphere due to premature birth. In addition, this is the phase that causes the inhibition of retinal vascularisation in the immature retina resulting from a reduction in the release of vascular endothelial growth factor (VEGF), while receiving $\mathrm{O}_{2}$ therapy due to the immature lungs. The release of $\mathrm{CD} 3$ polyunsaturated fatty acids, erythropoietin, insulin-like growth factor-binding protein is also reduced. In Phase 2, a proliferation of usually abnormal, and rarely normal, vessels appear due to the release of hypoxia-related VEGF resulting from inhibition of retinal vascularisation.

Phase 1 is characterised by a reduction in insulin-like growth factor (IGF-1) in premature infants. Hypoxia arising due to undeveloped vessels is followed by the release of VEGF, which results in an increase in IGF-1 level. Decreases occur in levels of haemoglobin $(\mathrm{Hb})$, the protein that carries oxygen from the lungs to the tissues in the circulation, and in the haematocrit (Hct), for various reasons in infants with ROP, and these decreases may be an additional enhancing factor for VEGF secretion by increasing the retinal hypoxia in premature infants. The resulting cytokines are responsible for a destructive new vascularisation in the retina (Phase II ROP) [3]. Angiogenesis regulated by local release of proangiotic or angiogenic factors is a further critical step in the development pathological ROP [6]. According to recent findings, platelets are also involved in the development of angiogenesis and retinochoroidal vascular diseases [7] [8].

Various parameters, including platelet count, mean platelet volume (MPV) and platelet distribution width (PDW) are important indicators of platelet activity commonly used in clinical practice. Platelets with larger volume are metabolically and enzymatically more active when compared to small ones [9]. Studies have also been conducted on infants born of parents with increased MPV, together with platelet-related diseases, and the association with complications such as neonatal sepsis and neonatal inflammation [10]. In light of these data, the present study was conducted to investigate the possible correlation between the 
haematological parameters ( $\mathrm{Hb}$ and MPV, PDW and platelet counts) and the development of ROP by comparing the values in the first month, known as the period of ROP development, in premature infants who have developed and have not developed ROP.

\section{Materials and Methods}

We retrospectively analysed the $\mathrm{CBC}$ drawn within $<72$ hours of age and the first month haemogram results of premature infants born at 35 weeks of gestation and earlier with an average weight of 1550 grams or less and who did not have ROP or who developed ROP at different stages. The infants attended our ROP diagnosis and treatment centre between February 2016 and February 2017 and consisted of infants who were followed up in our hospital intensive care unit and who were referred to our centre for the diagnosis and treatment of ROP from outer centres. In total, 317 of the 786 infants-those that had a CBC drawn within 72 hours of birth, and had haemogram data for the first month. are included in the study. Infants that had undergone blood transfusion, had sepsis or were diagnosed with necrotising enterocolitis were excluded from the study. Additional exclusion criteria included gestational age greater than 35 weeks, birth weight greater than $2850 \mathrm{~g}$, and family history of refraction errors.

The study group consisted of infants with ROP and was evaluated according to the severity and prevalence of vascular proliferation following the instructions of the International Classification of Retinopathy of Prematurity (ICROP) 2005 [11]. The infants were divided into 4 groups: Group I (47 infants) with stage 0 1 disease, Group II (39 infants) with stage 1 - 2 disease, Group III (18 infants) with stage 3 disease and above and Group IV (24 infants) with no diffuse findings but showing a rapid progression from stage 1 to stage 5 and having Aggressive Posterior Retinopathy of Prematurity (APROP) (Type II or rush-type ROP which has the following characteristic: 1) more posterior location; 2) rapid progression rather than through the classic stages 1 - 5; and 3) poor prognosis despite early treatment) defined as a form usually seen in infants born at 28 weeks of gestation and earlier [12]. Only one infant in Group III was stage 4A and no infant had stage $4 \mathrm{~A}$ or 5 premature retinopathy. All examinations were carried out by the same physician after administering 2.5\% phenylephrine (Mydfrin, Alcon, USA) and $0.5 \%$ tropicamide (tropamide, BilimIlac, Turkey) eye drops 3 times at 10 minute intervals to dilate the pupil. Fundal views were recorded with an Archimed Medical video archiving system (Pronova, Ankara, Turkey).

Routine haemogram test results were obtained with LH780 Analysers (Beckman Coulter Inc., Fullerton, CA) and retrieved from the hospital data system.

\section{Statistics}

The IBM SPSS 21.0 software for Windows (Statistical Package for the Social Sciences, Chicago, USA) was used for statistical analysis of the data. Parameters with a normal distribution were evaluated using the Kolmogorov Smirnov test. 
Descriptive statistics were given as frequency and percentages for qualitative data, as mean \pm standard deviation for normally distributed quantitative data, and medians (minimum-maximum). The Mann-Whitney U test or Student's t-test was used to compare the variables. Correlation tests were used to correlate the data sets with each other. The Spearman test was used for correlation. A P value of less than 0.05 was considered statistically significant.

\section{Results}

The control group consisted of 189 premature babies with a mean gestational age of 31 (26 - 35) weeks and a birth weight of 1757 (820 - 2830) grams. The study group included 128 babies with a mean gestational age of 29 (23 - 35) weeks and a birth weight of $1332(490$ - 2850) grams and with ROP at different stages.

Table 1 lists the gestational week, birth weights and lengths of stay in incubators for the control and study group infants.

Measurements included red blood cell count $\left(\mathrm{RBC} ; 10^{6} \mathrm{~mL}\right)$, haemoglobin (HB; gr/L), haematocrit (HCT; \%), platelet count (PLT; $\left.10^{3} / \mathrm{mL}\right)$, mean corpuscular volume (MCV; fL), mean corpuscular haemoglobin ( $\mathrm{MCH}$; pg), mean corpuscular haemoglobin concentration ( $\mathrm{MCHC}$; $\mathrm{g} / \mathrm{dL}$ ), red cell distribution width (RDW; \%), mean platelet volume (MPV; fL) and platelet distribution width (PDW; \%).

During birth, the values of $\mathrm{RBC}, \mathrm{Hb}, \mathrm{MCV}, \mathrm{MCH}, \mathrm{RDW}$ were significantly lower $(\mathrm{p}<0.001)$ and the values of MCHC, PLT, MPV were significantly higher in the infants who developed ROP than in the infants who did not develop ROP. Likewise, the values of $\mathrm{Hb}, \mathrm{MCV}, \mathrm{MCH}, \mathrm{MCH}$, PLT were significantly lower but the values of RDW, MPV, PDW were significantly higher in haemogram results of infants born with ROP in the first month after birth $(\mathrm{p}<0.001)$ (Table 2).

Comparison of the subgroups of the study group with respect to MPV values revealed differences between the control group infants and the group I infants ( $p$ $=0.234)$, as well as the group II and group IV, although the differences were not statistically significant $(\mathrm{p}=0.415)$. However, the difference between the control group and group IV was statistically significant $(\mathrm{p}<0.001)$. A correlation test showed a weak correlation between the ROP stage and the gestational week ( $r=$ $-441 ; \mathrm{p}<0.001)$ and the birth weight $(\mathrm{r}=-449 ; \mathrm{p}<0.001)$ of the study group and the control group infants for the haemogram data in the first month. Again,

Table 1. Clinical characteristics of the control and study group infants.

\begin{tabular}{cccc}
\hline & Control Group & Study Group & $\mathrm{p}$ \\
\hline Gestational age (week) & $31(26-35)$ & $29(23-35)$ & $<0.001^{*}$ \\
Birth weight (gram) & $1757(820-2830)$ & $1332(490-2850)$ & $<0.001^{*}$ \\
Length of stay in incubator (day) & $24(2-120)$ & $46(6-195)$ & $<0.001^{*}$ \\
Gender(male/female) & $98 / 91$ & $74 / 54$ & 0.304
\end{tabular}

${ }^{*} \mathrm{p}<0.005$. 
Table 2. Statistical comparison of hemogram data of the control and study group infants in the first month.

\begin{tabular}{ccccccc}
\hline & \multicolumn{2}{c}{ Control Group } & \multicolumn{2}{c}{ PStudy Group } & Study $^{*}$ & $\mathrm{p}$ \\
\hline $\mathrm{RBC}\left(10^{\wedge} 6 \mathrm{~mL}\right)$ & $4.7(1)$ & $3.1(0.8)$ & $<0,001^{*}$ & $3.2(0.9)$ & $3.2(0.8)$ & 0.306 \\
$\mathrm{Hb}(\mathrm{gr} / \mathrm{L})$ & $17.9(3.6)$ & $9.5(2.3)$ & $<0,001^{*}$ & $10.3(3.3)$ & $9.9(2.2)$ & $0.004^{*}$ \\
$\mathrm{Hct}(\%)$ & $52.4(9.5)$ & $27.8(6.5)$ & $<0.001^{*}$ & $30.1(3.3)$ & $28.2(7.5)$ & 0.010 \\
$\mathrm{PLT}(10 \wedge 3 / \mathrm{mL})$ & $229(87)$ & $299.5(176)$ & $<0.001^{*}$ & $367(194)$ & $308.5(208)$ & $<0.001^{*}$ \\
$\mathrm{MCV}(\mathrm{fL})$ & $110(9.6)$ & $90(8.4)$ & $<0.001^{*}$ & $93(6.5)$ & $90(8.8)$ & $<0.001^{*}$ \\
$\mathrm{MCH}(\mathrm{pg})$ & $36.8(3.9)$ & $30.8(2.9)$ & $<0.001^{*}$ & $32.4(2.2)$ & $30.9(3)$ & $<0.001^{*}$ \\
$\mathrm{MCHC}(\mathrm{g} / \mathrm{dL})$ & $33.5(1.6)$ & $34(1.3)$ & $<0.001^{*}$ & $34.4(1)$ & $33.9(1.3)$ & $<0.001^{*}$ \\
$\mathrm{RDW}(\%)$ & $18.7(2.9)$ & $16.9(3.3)$ & $<0.001^{*}$ & $16.9(2.2)$ & $17.8(3.1)$ & $<0.001^{*}$ \\
$\mathrm{MPV}(\mathrm{fL})$ & $7.9(1.1)$ & $9.3(1.8)$ & $<0.001^{*}$ & $8.3(1.3)$ & $9.2(1.9)$ & $<0.001^{*}$ \\
$\mathrm{PDW}(\%)$ & $17.6(1)$ & $17.2(1.3)$ & 0.576 & $17.1(1.3)$ & $17.7(1.4)$ & $<0.001^{*}$ \\
\hline
\end{tabular}

Hemogram values of the control and study group in the first month. ${ }^{*} \mathrm{p}<0.005$. RBC $\left(10^{\wedge} 6 \mathrm{~mL}\right)$; red blood cell, $\mathrm{Hb}(\mathrm{gr} / \mathrm{L})$; hemoglobin, $\mathrm{HCT}(\%)$; hematocrit, $\mathrm{PLT}\left(10^{\wedge} 3 / \mathrm{mL}\right)$; platelet, $\mathrm{MCV}(\mathrm{fL})$; mean corpuscular volume, $\mathrm{MCH}(\mathrm{pg})$; mean corpuscular hemoglobin, $\mathrm{MCHC}(\mathrm{g} / \mathrm{dL})$; mean corpuscular hemoglobin concentration, $\mathrm{RDW}(\%)$; red cell distribution width, MPV(fL); mean platelet volume, $\mathrm{PDW}(\%)$; platelet distribution width.

a weak correlation was evident between the ROP stage and RBC $(\mathrm{r}=-0.72 ; \mathrm{p}=$ $0.2)$, HCT $(\mathrm{r}=-183 ; \mathrm{p}<0.001)$, PLT $(\mathrm{r}=-291 ; \mathrm{p}<0.001)$, MCV $(\mathrm{r}=-345 ; \mathrm{p}<$ $0.001, \mathrm{MCH}(\mathrm{r}=-260 ; \mathrm{p}<0.001)$, MCHC $(\mathrm{r}=-147 ; \mathrm{p}=0.009)$, RDW $(\mathrm{r}=174$; $\mathrm{p}=0002)$, MPV $(\mathrm{r}=314 ; \mathrm{p}<0.001)$, PDW $(\mathrm{r}=196 ; \mathrm{p}<0.001)$ and $\mathrm{HB}(\mathrm{r}=-211$; $\mathrm{p}<0.001$ ) (Table 3).

Modelling of birth Hb, PLT and MPV data following logistic regression analysis revealed a significant OR for Hb of $0.378(\mathrm{p}<0.001$, an OR for PLT of 1.004 that was not significant $(\mathrm{p}=0.2)$ and an OR for MPV of $2.595(\mathrm{p}=0.001)$ that was significant (Table 4). The modelling of Hb, PLT and MPV in the first month revealed a significant OR for Hb of 0.781 ( $\mathrm{p}<0.001$ ), for PLT of 0.997 ( $\mathrm{p}$ $=0.004)$ and for MPV of $1.421(\mathrm{p}=0.002)($ Table 5$)$.

\section{Discussion}

In our study, we detected a marked decrease in levels of $\mathrm{Hb}$, the oxygen carrier molecule, in infants with ROP. Oxygen transport is important during the development of ROP, and low levels of haemoglobin in infants with ROP can be a contributing factor to VEGF secretion from the hypoxic retina [8] [13] [14].

Although the PLT was significantly higher in the birth haemogram of the infants who developed ROP, it was significantly lower in the first month data, and especially lower in infants who developed advanced ROP and APROP. Thrombocytopenia has a known effect on the pathogenesis of ROP; for example, Chanra et al. [15] found intense subconjunctival haemorrhage after examining a patient with severe aggressive posterior ROP using a scleral depressor. Evaluation of that infant's blood values revealed the presence of idiopathic thrombocytopenic purpura (ITP) [15]. 
Table 3. Correlation between the stage of ROP development and hemogram parameters and gestational age-birth weight of infants.

\begin{tabular}{ccc}
\hline & STAGE & \\
\cline { 2 - 3 } & $\mathrm{r}$ & $\mathrm{p}$ \\
\hline Gestational age & -0.441 & $<0.001^{*}$ \\
Birth weight & -0.449 & $<0.001^{*}$ \\
RBC & -0.072 & 0.72 \\
Hb & -0.211 & $<0.001^{*}$ \\
MCHC & 0.147 & 0.009 \\
PLT & -0.291 & $<0.001^{*}$ \\
MCV & -0.345 & $<0.001^{*}$ \\
MCH & -0.260 & $<0.001^{*}$ \\
MPV & 0.314 & $0.002^{*}$ \\
PDW & 0.196 & $<0.001^{*}$
\end{tabular}

$\mathrm{P}<0.005$. RBC $\left(10^{\wedge} 6 \mathrm{~mL}\right)$; red blood cell, $\mathrm{Hb}(\mathrm{gr} / \mathrm{L})$; hemoglobin, $\mathrm{MCHC}(\mathrm{g} / \mathrm{dL})$; mean corpuscular hemoglobin concentration, PLT (10^3/mL); platelet, $\mathrm{MCV}$ (fL); mean corpuscular volume, $\mathrm{MCH}(\mathrm{pg})$; mean corpuscular hemoglobin, MPV(fL); mean platelet volume, $\mathrm{PDW}(\%)$; platelet distribution width.

Table 4. Multi-factor logistic regression analysis according to birth hemogram.

\begin{tabular}{ccc}
\hline & OR $(95 \%$ confidence interval $)$ & $\mathrm{p}$ \\
\hline $\mathrm{Hb}$ & $0.378(0.284-0.503)$ & $<0.001^{\star}$ \\
$\mathrm{PLT}$ & $1.004(0.998-1.010)$ & 0.2 \\
$\mathrm{MPV}$ & $5.595(1.495-1.504)$ & $0.001^{\star}$ \\
\hline
\end{tabular}

$\mathrm{P}<0.005^{\star} . \mathrm{Hb}(\mathrm{gr} / \mathrm{L})$; hemoglobin, $\mathrm{PLT}\left(10^{\wedge} 3 / \mathrm{mL}\right) ;$ platelet, $\mathrm{MPV}(\mathrm{fL}) ;$ mean platelet volume.

Table 5. Multi-factor logistic regression analysis according to hemogram in the first month.

\begin{tabular}{ccc}
\hline & OR $(95 \%$ confidence interval $)$ & $\mathrm{p}$ \\
\hline $\mathrm{Hb}$ & $0.781(0.693-0.880)$ & $<\mathbf{0 . 0 0 1 ^ { * }}$ \\
$\mathrm{PLT}$ & $0.997(0.995-0.999)$ & $\mathbf{0 . 0 0 4}^{*}$ \\
$\mathrm{MPV}$ & $1.421(1.137-1.777)$ & $\mathbf{0 . 0 0 2}^{*}$ \\
\hline
\end{tabular}

${ }^{*} \mathrm{p}<0.005 . \mathrm{Hb}(\mathrm{gr} / \mathrm{L}) ;$ hemoglobin, $\mathrm{PLT}\left(10^{\wedge} 3 / \mathrm{mL}\right)$; platelet, $\mathrm{MPV}(\mathrm{fL})$; mean platelet volume.

Other studies have demonstrated that a PLT below 100,000 during the development of ROP can trigger the development of severe APROP [16]. Vinekar et al. [16] have reported a regression of the ROP stages within 3 days following administration of aplatelet suspension to 10 infants with APROP plus (+) disease (abnormal vascular dilatation and tortuosity increase involving 2 or 3 quadrants) and advanced thrombocytopenia, and they obtained this regression without laser therapy. They attributed their findings to the functions of the platelets in regulating the transport of angiogenetic protein [16]. Platelets are also known to play 
a role in the abnormal vasculogenesis (phase 2) or abnormal angiogenesis (phase 1) underlying the pathoanatomy of severe ROP. In aggressive APROP, atypical and rapidly developing haemorrhages lead to the occurrence of APROP+ disease and the formations of flattened new blood vessels [11] [16] [17]. Thrombocyte growth factors (including VEGF-A) also play a role in the transport of the thrombospondin, cytokines and chemokines known as the stromal cell-derived factor. When the platelet count is low, platelets cannot perform this role [18].

Conversely, the MPV level was higher in both birth and first-month haemogram values of patients with ROP. MPV, another indicator of platelet function, is an important predictive factor for cardiovascular diseases in adults. It also has an important involvement in diseases such as diabetes, obesity, rheumatologic diseases, psoriasis and FMF [17] [18] [19]. Although only a small number of studies have focused on thrombocyte and platelet disorders in the development of ROP, transporter and cleaner characteristics have been demonstrated for these proteins (both pro- and anti-angiogenetic) that regulate angiogenesis. Both proangiogenetic and antiangiogenic agents are stored in different subpopulations of a-granules in platelets and megakaryocytes, and when a signal is received, these factors are gradually released. The possible roles of active platelets in the pathogenesis of ROP can be explained in this way [18].

The correlation between MPV and the likelihood of ROP development has been investigated previously by Cekmez et al. [20], who found no difference between a control group and infants with ROP. However, in that study, the blood samples were obtained from the infants within the first 2 hours immediately after birth, whereas the critical period for the development of ROP is postmenstrual 31 - 34 weeks. In fact, our data indicate significantly higher values for MPV in the haemogram data obtained in the first month in infants with and without ROP, and especially in group IV infants with ROP. This demonstrates a role for active thrombocytes in the development of ROP.

In our study, the PDW increase was significantly higher in the first month in the haemogram data of infants with and without ROP $(p<0.001)$. One of the platelet function indicators is the platelet distribution range (PDW) and related increases in the heterogeneity of the platelet volume distribution. In adult diabetic retinopathy patients, PDW values were significantly higher in patients with T2 DM than in controls [19]. A study conducted by Sadiq et al. in 2015 [8] also demonstrated the importance of platelet-derived growth factor (PDGF) in the angiogenesis cascade of retinochoroidal vascular diseases, such as diabetic retinopathy, retinal vein occlusion, age-related macular degeneration, pathological myopia and ROP. To the best of our knowledge, the present study is the first to examine the role of PDW in patients with ROP.

In the present study, we found that premature infants with ROP had low PLT and $\mathrm{Hb}$ values and increased MPV and PDW values in early postnatal life when compared with premature infants without this disease. These factors may therefore be useful in ROP diagnosis, follow-up and treatment of $\mathrm{O}_{2}$-mediated blood parameters and in the angiogenesis stages of ROP. 


\section{References}

[1] Hah, P.K., Prabhu, V., Karandikar, S.S., Ranjan, R., Narendran, V. and Kalpana, N. (2016) Retinopathy of Prematurity: Past, Present and Future. World Journal of Clinical Pediatrics, 5, 35-46. https://doi.org/10.5409/wjcp.v5.i1.35

[2] Chew, E.Y. (1999) Major Clinical Trials of Vitreoretinal Diseases. In: Regillo, C.D., Brown, G.C. and Flyn, H.W., Eds., Vitreoretinal Disease: The Essentials, Theme Medical Publisher Inc, New York, 667-677.

[3] Pudraza, W., Pudraza, H., Jezierska, K., Szwed, J., Modrejewska, M., Rudnicki, J., Kordek, A. and Domek, H. (2011) The Role of Hemoglobin Variant Replacement in Retinopathy of Prematurity. The Indian Journal of Pediatrics, 78, 1498-1502. https://doi.org/10.1007/s12098-011-0460-7

[4] Rothman, A.L., Mangalesh, S., Chen, X. and Toth, C.A. (2016) Optical Coherence Tomography of the Preterm Eye: From Retinopathy of Prematurity to Brain Development. Eye and Brain, 8, 123-133.

[5] Gilbert, C. (2008) Retinopathy of Prematurity: A Global Perspective of the Epidemics, Population of Babies at Risk and Implications for Control. Early Human Development, 84, 77-82. https://doi.org/10.1016/j.earlhumdev.2007.11.009

[6] Rivera, J.C., Sapieha, P., Joyal, J.S., Dulhamel, F., Shao, Z., Sitaras, N., Picard, E., Hardy, P., Lachapella, P. and Chemtob, S. (2010) Understanding Retinopathy of Prematurity: Update on Pathogenesis. Neonatology, 100, 343-353. https://doi.org/10.1159/000330174

[7] Patzelt, J. and Langer, H.F. (2012) Platelets in Angiogenesis. Current Vascular Pharmacology, 10, 570-577. https://doi.org/10.2174/157016112801784648

[8] Sadiq, M.A., Hanout, M,. Sarwar, S., Hassan, M., Do, D.V., Nquyen, Q.D. and Sepah, Y.J. (2015) Platelet Derived Growth Factor Inhibitors: A Potential Therapeutic Approach for Ocular Neovas Cularization. European Journal of Ophthalmology, 29, 287-291. https://doi.org/10.1159/000438953

[9] Chu, S.G., Becher, R.C., Berger, P.B., Bhatt, D.L., Eikelboom, J.W., Konkle, B., Mohler, E.R., Reilly, M.P. and Berger, J.S. (2010) Mean Platelet Volume as a Predictor of Cardiovascular Risk: A Systematic Review and Meta-Analysis. Journal of Thrombosis and Haemostasis, 8, 148-156. https://doi.org/10.1111/j.1538-7836.2009.03584.x

[10] Gionia, S., Piazze, J., Anceschi, M.M., Cerekia, A., Alberini, A., Giancotti, A., Larciprete, G. and Cosmi, E.V. (2007) Mean Platelet Volume: Association with Adverse Neonatal Outcome. Platelets, 18, 284-288. https://doi.org/10.1080/09537100601078448

[11] International Committee for the Classification of Retinopathy of Prematurity (2005) The International Classification of Retinopathy of Prematurity Revisited. Archives of Ophthalmology, 123, 991-999.

[12] Ahn, S.J., Kim, J.H., Kim, S.J. and Yu, Y.S. (2013) Capillary-Free Vascularized Retina in Patients with Aggressive Posterior Retinopathy of Prematurity and Late Retinal Capillary Formation. Korean Journal of Ophthalmology, 27, 109-115.

[13] Lubetzky, R., Stolovitch, C. and Dolberg, S. (2005) Nucleated Red Cells in Preterm Infants with Retinopathy of Prematurity. Pediatrics, 116, 619-622. https://doi.org/10.1542/peds.2005-0915

[14] Kandasamy, Y., Kumar, P. and Hartley, L. (2014) The Effect of Erythropoietinon the Severity of Retinopathy of Prematurity. Eye (Lond), 28, 814-818.

[15] Chandra, P., Kumawat, D., Kumar, V. and Tewari (2017) Bilateral Large 
Subconjunctival Haemorrhages Unmasking İmmune Thrombocytopenic Purpura during Retinopathy of Prematurity Screening. BMJ Case Reports. https://doi.org/10.1136/bcr-2017-221444

[16] Vinekar, A., Hegde, K., Gilbert, C., Braganza, S., et al. (2010) Do Platelets Have a Role in the Pathogenesis of Aggressive Posterior Retinopathy of Prematurity. Retina, 30, 520-523. https://doi.org/10.1097/IAE.0b013e3181cafc30

[17] İlhan, D., Özbabalık, D., Gülcan, E., Özdemir, O. and Gülbağ, S.Z. (2010) Evaluation of Platelet Activation, Coagulation, and Fibrinolytic Activation in Patients with Symptomatic Lacunar Stroke. Neurologist, 16, 188-191.

https://doi.org/10.1097/NRL.0b013e318198d8bc

[18] Tao, Y., Dong, Y., Lu, C.W. and Li, Q. (2015) Relationship between Mean Platelet Volume and Retinopathy of Prematurity. Graefe's Archive for Clinical and Experimental Ophthalmology, 253, 2972-2978.

[19] Akdogan, M., Budak, Y.U. and Huysal, K. (2016) The Association of Hematologic Inflammatory Markers with Atherogenic Index in Type 2 Diabetic Retinopathy Patients. Clinical Ophthalmology, 10, 1797-1801.

https://doi.org/10.2147/OPTH.S110749

[20] Çekmez, F., Tanju, İ.A., Canpolat, F.E., Aydinoz, S., Aydemir, G., Karademir, F. and Sarıc1, S.U. (2013) Mean Platelet Volume in Very Preterm Infants: A Predictor of Morbidities? European Review for Medical and Pharmacological Sciences, 17, 134-137. 